\title{
Suggestions from the Blue Jay Booksh
}

Sub P.O. 8, 1210 - 7th Avenue N., Saskatoon, Saskatchewan. S7K 2W2

AVONLEA YESTERDAY AND TODAY: Archaeology and Prehistory. Edite

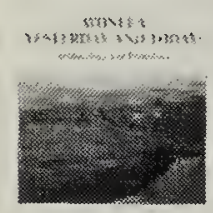

Leslie B. Davis. 1988. The proceedings of a posium held in Regina this volume contains $p$ which deal with every aspect of the Avonlea ma culture whose type site is located 50 miles sou, Moose Jaw in southern Saskatchewan. $313 \mathrm{pp} . \$$ i $_{3}$ softcover

OUT OF THE PAST: Sites, Digs and Artifacts in the Saskatoon Area. Edite

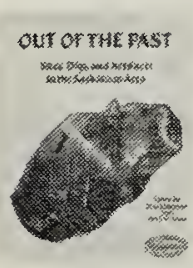

Urve Linnamae and Tim E. H. Jones. 1988. This presents a major collection of papers on archae in the Saskatoon area but its material is of interest a Saskatchewan residents. It is a solid contribution th ongoing effort of interpretation and presenting the " of our past. 191 pp. \$15.95 softcover

FROZEN IN TIME: Unlocking the secrets of the Franklin Expedition. Owen B

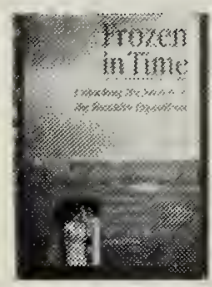
and John Geiger. 1988. From the ice-shrouded $\mathrm{gr}$ ? three 19th-century seamen reveal the chilling fate doomed Arctic expedition. A superb account it color photographs of the grave sites. 179 pp. \$:9 hardcover

WOLVES. Candace Savage. 1988. A photographic essay of the wolf, once the

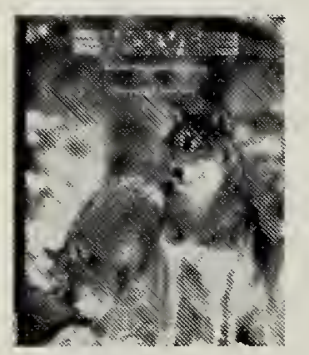
widely distributed land mammal in the $\mathrm{w} / \mathrm{c}$ Together the dramatic photographs, maps and ser $v$ text create a celebration of wolves and serve reminder that the reality of nature is infinitely or fascinating than myth. 159 pp. $\$ \mathbf{3 5 . 0 0}$ hardcove

OSPREYS: A natural and unnatural history. Alan F. Poole. 1989. In a cle $n$

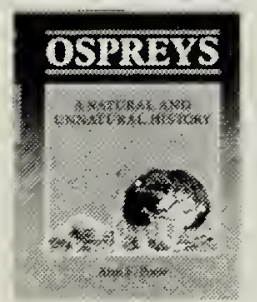
entertaining style, the author tkes an up-to-date $\mathrm{ld}$ i the natural history of this popular bird. The osp a major symbol of international conservation, w it populations once threatened but now restored in t New England and Scotland. Includes photo ni sketches. 272 pages. $\$ \mathbf{3 4 . 0 0}$ hardcover.

THE ARCTIC WOLF - LIVING WITH THE PACK. L. David Mech. 1988. This 10 docuements the authors experiences with the ti wolf on Ellesmere Island and provides valis docuementation of wolf behaviour and of variou ici dents in the life of the wolf pack. 100 full color $p$ os 128 pages. List price of $\$ 19.95$; Special price of $\$$ softcover. 